University of Wollongong

Research Online

Faculty of Engineering and Information

Faculty of Engineering and Information

Sciences - Papers: Part B

Sciences

2019

Evaluation of data-driven models for predicting the service life of concrete sewer pipes subjected to corrosion

\author{
Xuan Li \\ University of Queensland \\ Faezehossadat Khademi \\ Illinois Institute of Technology \\ Yiqi Liu \\ South China University of Technology \\ Mahmoud Akbari \\ University of Kashan \\ Chengduan Wang \\ Sichuan University of Arts and Science
}

See next page for additional authors

Follow this and additional works at: https://ro.uow.edu.au/eispapers1

Part of the Engineering Commons, and the Science and Technology Studies Commons

Research Online is the open access institutional repository for the University of Wollongong. For further information contact the UOW Library: research-pubs@uow.edu.au 


\title{
Evaluation of data-driven models for predicting the service life of concrete sewer pipes subjected to corrosion
}

\author{
Abstract \\ Concrete corrosion is one of the most significant failure mechanisms of sewer pipes, and can reduce the \\ sewer service life significantly. To facilitate the management and maintenance of sewers, it is essential to \\ obtain reliable prediction of the expected service life of sewers, especially if that is based on limited \\ environmental conditions. Recently, a long-term study was performed to identify the controlling factors of \\ concrete sewer corrosion using well-controlled laboratory-scale corrosion chambers to vary levels of $\mathrm{H} 2 \mathrm{~S}$ \\ concentration, relative humidity, temperature and in-sewer location. Using the results of the long-term \\ study, three different data-driven models, i.e. multiple linear regression (MLR), artificial neural network \\ (ANN), and adaptive neuro fuzzy inference system (ANFIS), as well as the interaction between \\ environmental parameters, were assessed for predicting the corrosion initiation time (ti) and corrosion \\ rate $(r)$. This was performed using the sewer environmental factors as the input under 12 different \\ scenarios after allowing for an initiation corrosion period. ANN and ANFIS models showed better \\ performance than MLR models, with or without considering the interactions between environmental \\ factors. With the limited input data available, it was observed that ti prediction by these models is quite \\ sensitive, however, they are more robust for predicting $r$ as long as the H2S concentration is available. \\ Using the $\mathrm{H} 2 \mathrm{~S}$ concentration as a single input, all three data driven models can reasonably predict the \\ sewer service life.

\section{Disciplines} \\ Engineering | Science and Technology Studies

\section{Publication Details} \\ Li, X., Khademi, F., Liu, Y., Akbari, M., Wang, C., Bond, P. L., Keller, J. \& Jiang, G. (2019). Evaluation of data- \\ driven models for predicting the service life of concrete sewer pipes subjected to corrosion. Journal of \\ Environmental Management, 234 431-439.
}

\section{Authors}

Xuan Li, Faezehossadat Khademi, Yiqi Liu, Mahmoud Akbari, Chengduan Wang, Philip Bond, Jurg Keller, and Guangming Jiang 
2 Xuan Li ${ }^{\text {a }}$, Faezehossadat Khademi ${ }^{\text {b }}$, Yiqi Liu ${ }^{c}$, Mahmoud Akbari ${ }^{\mathrm{d}}$, Chengduan Wang ${ }^{\mathrm{e}}$, Philip L. Bond

${ }^{c}$ School of Automation Science \& Engineering, South China University of Technology, Guangzhou

7 510640, China

${ }^{\mathrm{d}}$ Civil Engineering Department, University of Kashan, Kashan, Iran

${ }^{\mathrm{e}}$ Department of Chemistry and Chemical Engineering, Sichuan University of Arts and Science, Sichuan,

10 China

XL: xuan.li@awmc.uq.edu.au; FK: faezehossadat khademi@yahoo.com; YL: aulyq@scut.edu.cn; MA: makbari@kashanu.ac.ir; CW: wcd@suse.edu.cn; PB: p.bond@uq.edu.au; JK: j.keller@uq.edu.au

* Corresponding author. E-mail: g.jiang@awmc.uq.edu.au; guangming.jiang@gmail.com; Tel.: +61 7 3346 3219; Fax: +61733654726 . 
Highlights:

- Data-driven models were developed for predicting the service life of concrete sewers based on various environmental conditions

- Interactions between the input environmental parameters affecting predictions for the three datadriven models were detected

- Model performance was systematically evaluated for 12 scenarios of partial inputs

- Sewer service life can be reasonably predicted by use of $\mathrm{H}_{2} \mathrm{~S}$ concentration alone 8 29 30 1 32 33 4 36

.




\section{Abstract}

61

Concrete corrosion is one of the most significant failure mechanisms of sewer pipes, and can reduce the sewer service life significantly. To facilitate the management and maintenance of sewers, it is essential to obtain reliable prediction of the expected service life of sewers, especially if that is based on limited environmental conditions. Recently, a long-term study was performed to identify the controlling factors of concrete sewer corrosion using well-controlled laboratory-scale corrosion chambers to vary levels of $\mathrm{H}_{2} \mathrm{~S}$ concentration, relative humidity, temperature and in-sewer location. Using the results of the long-term study, three different data-driven models, i.e. multiple linear regression (MLR), artificial neural network (ANN), and adaptive neuro fuzzy inference system (ANFIS), as well as the interaction between environmental parameters, were assessed for predicting the corrosion initiation time $\left(t_{\mathrm{i}}\right)$ and corrosion rate $(r)$. This was performed using the sewer environmental factors as the input under 12 different scenarios after allowing for an initiation corrosion period. ANN and ANFIS models showed better performance than MLR models, with or without considering the interactions between environmental factors. With the limited input data available, it was observed that $t_{i}$ prediction by these models is quite sensitive, however, they are more robust for predicting $r$ as long as the $\mathrm{H}_{2} \mathrm{~S}$ concentration is available. Using the $\mathrm{H}_{2} \mathrm{~S}$ concentration as a single input, all three data driven models can reasonably predict the sewer service life.

Keywords: Sewer corrosion, Service life, Data-driven models, Artificial Neural Network, Adaptive Neuro Fuzzy Inference System 
65

ANFIS Adaptive neuro fuzzy inference system

66 ANN

Artificial neural network

67 DDM

Data driven models

68 GP

Gas-phase

$69 \quad \mathrm{MICC}$

Microbially induced concrete corrosion

$70 \quad$ MLR

Multiple linear regression

$71 \quad$ PS

Partially-submerged

$72 \mathrm{RH}$

Relative humidity

73

74 


\section{Introduction}

Sewer networks are one of the most critical components of the urban infrastructure in modern societies. In addition to collecting and transporting the sewage, sewers play a critical role in preventing human exposure to unhygienic sewage and lower the risk of sewage-borne diseases. The total estimated asset value of these networks is reported to be about one trillion dollars in USA and 100 billion dollars in Australia (Jiang et al., 2015a). However, severe structural deterioration and early failure of sewers occurs world-wide. Various factors including sewer materials, load stress, subsoil characteristics and corrosion, etc., affect the process of sewer deterioration (Baur and Herz, 2002). Whereas, corrosion is reported as the primary cause for the sewer deterioration, which weakens the structural capacity of the sewer and may ultimately lead to its collapse and failure (Kaempfer and Berndt, 1999; Tee et al., 2011). The replacement and rehabilitation of these damaged sewers is implemented at great expense. In the USA alone this expenditure is about 14 billion USD per year, and this is increasing yearly as the aging infrastructure continues to fail (Alexander et al., 2013; Jiang et al., 2016a).

Concrete sewer corrosion is prevalent where high levels of hydrogen sulfide $\left(\mathrm{H}_{2} \mathrm{~S}\right)$ in the headspace gas occurs (Parker, 1945; Jiang et al., 2017; Song et al., 2018). It is a long-term process with chemical, physical and biological contributing factors. $\mathrm{H}_{2} \mathrm{~S}$, directly or after being oxidized by sulfide-oxidizing bacteria into sulfuric acid, reacts with the concrete to cause its corrosion (Joseph et al., 2012). This is often called microbially induced concrete corrosion (MICC). During these chemical and biological reactions, the corrosion process is highly affected by the environmental factors of hydrogen sulfide concentration, humidity and temperature (Jiang et al., 2014). Within the sewer, the concrete corrosion mostly occurs on the regions just above the sewage flow level and at the ceiling of the headspace. These regions are respectively referred to as the "tidal region" and the "crown region" (Li et al., 2017). With or without fluctuated wastewater level, corrosion are often more severer in the tidal regions than the crown regions (Jiang et al., 2014; Cayford et al., 2017). 
To control sewer corrosion, different methods for removing or reducing the levels of hydrogen sulfide are proposed by dosing the sewage with chemicals, such as nitrate, oxygen, or iron salts (Zhang et al., 2009; Jiang et al., 2011; Jiang et al., 2013). Free nitrous acid (FNA), an antibacterial agent, has been applied to sewers and found to successfully inhibit the $\mathrm{H}_{2} \mathrm{~S}$ formation and the MICC (Jiang et al., 2011; Sun et al., 2015) . To mitigate sewer corrosion problems corrosion-resistant materials are used for constructing new sewers and protective coatings are applied to corroded concrete surfaces (Chang et al., 2005; De Muynck et al., 2009).

To perform efficient sewer maintenance and rehabilitation, as well as for optimizing the numerous controlling factors, the sewer service life needs to be predicted with reasonable accuracy. Existing sewer corrosion prediction models mainly focus on the physicochemical and biological processes in the wastewater or sewer air phase. These processes can include the hydrogen sulfide production or partition between phases, or the characteristics of wastewater along the sewer (Nielsen et al., 2003; Sharma et al., 2008; Ganigue et al., 2011). Modeling concrete corrosion in sewers is difficult as the processes are complicated and there is a scarcity of corrosion measurements. In contrast to process models, the sewer service life can be estimated using a bilinear corrosion model (Wells and Melchers, 2015). In a standard reinforced concrete sewer pipe, the service life ends once the metal reinforcing exposes to sewer air (Wells and Melchers, 2014). The sewer service life ( $L$, year) is typically estimated using the time for corrosion to initiate $\left(t_{\mathrm{i}}\right.$, months) and the corrosion rate $(r$, concrete depth lost over time, $\mathrm{mm} / \mathrm{year})$, as shown in equation (1) (Jiang et al., 2016a).

$$
L=\frac{t_{i}}{12}+\frac{D}{r}
$$

Where $D$ represents the initial depth of concrete cover separating the metal reinforcing structure from the sewer atmosphere, which is the maximum loss of concrete depth before structural failure (mm) (Wells and Melchers, 2014). However, this model is only indirectly related to the environmental conditions of the sewer. In the absence of a process model for the corrosion initiation time $\left(t_{\mathrm{i}}\right)$ and corrosion rate $(r)$, it is still difficult to simulate the corrosion development and service life prediction. 
Recent studies show that both the corrosion initiation time and the corrosion rate are dependent on the sewer environmental conditions of cross-sectional location, gaseous $\mathrm{H}_{2} \mathrm{~S}$ concentrations, temperature, and relative humidity (Jiang et al., 2014; Jiang et al., 2015b). These studies have also generated extensive measured datasets for the development and progress of corrosion in well controlled laboratory-scale experiment chambers. From the results of these studies there is potential to estimate both the initiation time for corrosion and the corrosion rate using data-driven models (DDM). Our recent work shows that the artificial neural network (ANN), a data-driven model, is a reliable technique for predicting concrete corrosion of sewers by comparing with multiple linear regression (MLR) models(Jiang et al., 2016a).

In addition to the ANN model, other DDM such as multiple linear regression (MLR) and adaptive neuro fuzzy inference system (ANFIS) have been widely used in the fields of civil engineering and wastewater treatment. ANN models have been used efficiently for approximating the corrosion current density of reinforced concrete (Sadowski and Nikoo, 2014), for predicting the compressive strength of concretes (Khademi and Behfarnia, 2016) and for describing membrane bioreactors (Dalmau et al., 2015). In contrast, MLR models have been used to determine the preliminary design mix of concrete based on compressive strength requirements (Khademi and Behfarnia, 2016). Additionally, ANFIS, a novel neuro-fuzzy approach, has been widely used for predicting unknown nonlinear dynamics in hydraulic systems (Chang and Chang, 2006), to determine concrete strength (Topcu and Sarıdemir, 2008; Amani and Moeini, 2012) and for bridge risk assessment (Wang and Elhag, 2008). To date, ANFIS models have not been applied for predicting sewer corrosion processes.

This study aims to evaluate three different data driven models - MLR, ANN and ANFIS for predicting the service life of sewers under different environmental condition scenarios. The two main outputs, corrosion initiation time $\left(t_{\mathrm{i}}\right)$ and corrosion rate $(r)$, were determined based on the environmental parameters that are identified as the controlling factors of sewer corrosion. Typically, it is very difficult to obtain comprehensive datasets of relevant sewer environmental conditions for prediction purposes. Hence, we 
show in this instance it was possible to assess the model robustness and accuracy of predictions using partial input parameters.

\section{Materials and Methods}

\subsection{Sewer corrosion data through long-term tests in corrosion chambers}

Previously, long-term corrosion studies have generated extensive corrosion parameters including both corrosion rates and corrosion initiation times (Jiang et al., 2014; Jiang et al., 2015b). The long-term corrosion tests were carried out on concrete coupons within simulated conditions of real sewers that were maintained in a total of thirty-six laboratory corrosion chambers. The testing variables of the study combined two different locations of the concrete coupons (gas-phase (GP) and partially-submerged (PS) in real wastewater), two levels of relative humidity $(\mathrm{RH})(100 \%$ and $90 \%)$, six gas phase $\mathrm{H}_{2} \mathrm{~S}$ levels (0 ppm, $5 \mathrm{ppm}, 10 \mathrm{ppm}, 15 \mathrm{ppm}, 25 \mathrm{ppm}$ and $50 \mathrm{ppm})$, and three gas-phase temperatures $\left(17^{\circ} \mathrm{C}, 25^{\circ} \mathrm{C}\right.$, and $\left.30^{\circ} \mathrm{C}\right)$ (Jiang et al., 2014). The locations of the coupons in the chambers were representative of the sewer crown (gas-phase) and tidal regions (partially submerged). The range of relative humidity, temperature and $\mathrm{H}_{2} \mathrm{~S}$ concentrations were chosen based on real sewer conditions (Wells et al., 2012). To study both the corrosion initiation and the active corrosion periods in the sewer environment, we examined the exposure of new concrete pipe coupons, made from a new sewer pipe (1.2 m diameter and $0.07 \mathrm{~m}$ thickness, HUMES, Sydney, Australia), and the exposure of pre-corroded coupons, prepared from corroded concrete sewer slabs obtained from Sydney Water Corporation, Australia. The coupons were embedded in stainless steel frames using an epoxy resin (FGI R180 epoxy and H180 hardener). The steel frame providing a reference point to determine the change in coupon thickness caused by the corrosion (Jiang et al., 2014). The coupons were arranged so the original internal surface of the sewer pipe was the exposed testing surface for the corrosion development in the corrosion chambers (Figure-S1).

The corrosion chambers were operated continuously for 4.5 years between $2009-2014$ with eight pairs of enclosed coupons exposed under each of the 36 environmental conditions. Systematic and detailed analysis was conducted at intervals between 6 and 10 months depending on the corrosion development. For each 
sampling event, a set of coupons containing one pair of partially submerged coupons and one pair of gas phase coupons were retrieved for analysis. The corrosion initiation time was determined based on the time to achieve a detectable level of sulfate on the fresh concrete samples and the corrosion rate was determined from the measured change of thickness on the pre-corroded concrete samples per year (Jiang et al., 2014; Jiang et al., 2015b). The corrosion data obtained from this lab investigation were used to evaluate the three selected data-driven models for the prediction of the corrosion process.

\subsection{Data-driven models for predicting sewer corrosion}

\subsubsection{Multiple Linear Regression}

The corrosion initiation time and corrosion rate datasets were used for independent analysis before establishing MLR models. First, independence analysis of input variables was carried out using R (ver. 3.03, http://www.R-project.org/). A total of 60 data points were used for independence analysis of corrosion initiation time, whereas after the initiation period, a total of 72 data points were used for the independence analysis of corrosion rate. The categorization of location (Location), relative humidity $(\mathrm{RH}, \%)$, temperature $\left(T,{ }^{\circ} \mathrm{C}\right)$ and $\mathrm{H}_{2} \mathrm{~S}$ concentration $\left(H_{2} \mathrm{~S}, \mathrm{ppm}\right)$ were chosen as input variables for the prediction of corrosion rate $(r)$ and initiation time $\left(t_{\mathrm{i}}\right)$. The interaction between these variables were analyzed and the significance of the interaction was assessed using the F-test.

The multiple linear regression typically generates the correlation in terms of a straight line which best approximates all the individual data points including target and output parameters (Deshpande et al., 2014; Khademi and Behfarnia, 2016). The general form of the MLR is given as equation 2:

$$
\hat{\mathrm{Y}}=a_{0}+\sum_{j=1}^{m} a_{j} X_{j}
$$

Where $\hat{\mathrm{Y}}$ is the model's output, $X_{j}$ is the independent input variables to the model, and $a_{0}, a_{1}, a_{2}, \ldots, a_{m}$ are the partial regression coefficients.

To build the multiple linear regression models, results obtained from the independence analysis for the interaction between input factors were included. Additionally, in order to have a clear view of both gas 
phase coupons and partially submerged coupons, datasets were separated by location to build separate models. The coefficients for each of the input variables in each model were determined with associated standard error.

\subsubsection{Artificial Neural Network}

ANN is capable of learning from the provided data, as the correlation between the input and output parameters of ANN are created by the data themselves. One of the most significant characteristics of ANN is that it is efficient in solving incomplete tasks and producing approximate outcomes. Basically, an ANN model contains 3 layers that are the input, hidden, and output layers. With several input variables and one or multiple hidden layers, the output layer is generated at very high accuracy (Khademi and Jamal, 2016). Various nodes can be utilized to estimate any measurable functional correlation in the hidden layer. However, in general, using a single hidden layer is adequate and highly recommended. As such, the single hidden layer structure was adopted in the current study.

Each neuron in any particular layer is linked to several other nodes using weighted connections. The weights imply the strength of connections between the interconnected neurons (Garzón-Roca et al., 2013) and are trained to make the output values similar to the target values of the data set. The general procedure of building an ANN model uses the steps of training, validation, and test. The most significant role of the training step is to minimize the error function, i.e. the mean square error (MSE). The validation step performs independently from the training step and is used to construct the model. Finally, the machine learning algorithm accuracy is estimated in the test step. In order to ensure that all variables produce comparable impacts during the training process, the variables are scaled to the range $(0,1)$ by using the original data range of the corresponding variable as a scalar.

In this study, the ANN is used to predict both the corrosion initiation time and corrosion rate after the initiation period based on the sewer environmental factors. The input variables in the ANN model are location, $\mathrm{RH}(\%)$, Temperature $\left({ }^{\circ} \mathrm{C}\right)$, and $\mathrm{H}_{2} \mathrm{~S}(\mathrm{ppm})$. The structure of the model is exhaustively searched to determine the optimal number of neurons in the hidden layer using Alyuda Neuro Intelligence ver. 2.2. 
The final structure is used to predict the corrosion initiation time and the rate using MATLAB software (R2015b). The sigmoidal tangent function was selected for hidden nodes and a linear activation function was selected for the output layer. Among the different algorithms tested, the Levenberg-Marquardt (LM) algorithm was selected based on its suitability.

The training and testing were carried out based on the established overall structure of the model. Hence, the amount of data in the training set plays a vital role. A total of 60 data points were used for the modeling to obtain the corrosion initiation time and a total of 72 data points were used for the modeling to obtain the corrosion rate after the initiation period. Based on the data set, the suggested amount of training data was set to be equal or more than 60 percent of the total data. With respect to the training data set, the proportion of observations per data in this study was set as $70 \%, 15 \%$ and $15 \%$ for the training, validation and test steps, respectively.

\subsubsection{Adaptive Neuro Fuzzy Inference System}

The adaptive neuro fuzzy inference system, known as ANFIS, is a widely-accepted tool for estimating complex problems. ANFIS combines ANN with the human-like reasoning style of fuzzy inference systems (FIS) through the use of fuzzy sets and a linguistic model containing a set of IF-THEN fuzzy rules. As one of the most well-known application fuzzy logic theory, FIS has the structured awareness where each fuzzy rule illustrates a local behavior of the system. The FIS model performs like a white box, where the model designers can discover how the model achieved its goal (Karaboga and Kaya, 2018). However, FIS lacks the adaptability to handle any changes in the outside environment. Accordingly, neural network systems are combined with the fuzzy inference system, resulting in ANFIS. In the network, the back propagation, which is the fundamental learning algorithm, minimizes the estimation error (Madandoust et al., 2012). Therefore, in ANFIS, both the learning capabilities of the neural network and reasoning capabilities of the fuzzy logic are merged. In ANFIS, the nodes and the hidden layers of neuron network are determined precisely by a FIS. This eliminates the well-known difficulty of determining the hidden layer of ANN 
models and at the same time improving its prediction capability (Abdulshahed et al., 2015). The fuzzy reasoning mechanism of ANFIS model is shown in the rules below:

Rule 1: IF $\mathrm{x}$ is $\mathrm{A}_{1}$ and $\mathrm{y}$ is $\mathrm{B}_{1}$, THEN $\mathrm{f}_{1}=\mathrm{p}_{1}+\mathrm{q}_{1}+\mathrm{r}_{1}$.

Rule 2: IF $\mathrm{x}$ is $\mathrm{A}_{2}$ and $\mathrm{y}$ is $\mathrm{B}_{2}$, THEN $\mathrm{f}_{2}=\mathrm{p}_{2}+\mathrm{q}_{2}+\mathrm{r}_{2}$.

Where $x$ and $y$ are the inputs, $A_{i}$ and $B_{i}$ are the fuzzy sets, $f_{i}$ are the outputs within the fuzzy region specified by the fuzzy rule, and $\mathrm{p}_{\mathrm{i}}, \mathrm{q}_{\mathrm{i}}$ and $\mathrm{r}_{\mathrm{i}}$ are the design parameters that are determined during the training process.

Due to the ability to account for uncertainties and adaptive features, ANFIS can have advantage over other data-driven models. Therefore, we used ANFIS to predict both the corrosion initiation time and corrosion rate after the initiation period based on the sewer environmental factors. The input variables in ANFIS modeling are location, $\mathrm{RH}(\%)$, temperature $\left({ }^{\circ} \mathrm{C}\right)$, and $\mathrm{H}_{2} \mathrm{~S}(\mathrm{ppm})$.

The whole dataset used for the ANFIS modelling was divided into different groups for the purpose of training, validation, and test. A total of 60 data points were used for the modeling to obtain the corrosion initiation time and a total of 72 data points were used for modeling to obtain the corrosion rate after the initiation period. With respect to the training data set, the proportion of observations per data in this study was set as $70 \%, 15 \%$ and $15 \%$ for the training, validation and test steps, respectively.

\subsection{Evaluation of the different data-driven models for predicting sewer corrosion}

\subsubsection{Comparison of the predicting performance}

Three different data-driven models were constructed using the same dataset and their performance was compared. The coefficients of determination $\left(\mathrm{R}^{2}\right)$ of the MLR models and correlation coefficients $(\mathrm{R})$ of the ANN and ANFIS models were employed as the indicators to assess the performance of each model in predicting the corrosion initiation time and corrosion rate.

\subsubsection{Assessment of the model robustness with partial input data}


Considering most often there is limited access to the measured conditions in the real sewer environments, it is highly important to assess the robustness of the model using incomplete datasets as the input. The resilience of models to incomplete data can be an important criterion for model application.

Our previous study suggests that not all the environmental factors are equally important for the prediction of sewer corrosion $t_{\mathrm{i}}$ and $r$ (Jiang et al., 2016a). For $t_{\mathrm{i}}, \mathrm{H}_{2} \mathrm{~S}$ and temperature are significant factors while $\mathrm{RH}$ has no significant effect. For the corrosion rate of concrete coupons, $\mathrm{H}_{2} \mathrm{~S}$ and $\mathrm{RH}$ were the significant controlling factors. Therefore, for different scenarios with partial input factors, the performance of each model may be different. Based on the nature of data and also the limited availability of real data as inputs to the model, 12 different combination scenarios with partial input factors (i.e. 4 input factors, 3 input factors, 2 input factors, 1 input factor) were chosen and comprehensive assessments under these scenarios with full set of data (i.e. 60 data points for $t, 72$ data points for $r$ ) were tested using MLR, ANN, and ANFIS models. The accuracy of prediction under each scenario was assessed using $\mathrm{R}^{2}$ values.

\section{Results and Discussion}

\subsection{Interaction analysis of input variables}

Testing independence of input variables for the prediction of corrosion initiation time and corrosion rate were determined from the interaction analysis. The interaction between each pair of sewer environmental input factors was tested and the significance of the interactions between the factors were determined using the F-test (Table 1).

Table 1. Interactions of the sewer environmental factors for the prediction of corrosion initiation time and corrosion rate

\section{Interactions \\ Prediction of initiation time \\ Prediction of corrosion rate}




$\begin{array}{llllll}\text { F Value } & \operatorname{Pr}(>\mathrm{F})^{\mathrm{a}} & \text { Significance }^{\mathrm{b}} & \mathrm{F} \text { Value } & \operatorname{Pr}(>\mathrm{F})^{\mathrm{a}} & \text { Significance }^{\mathrm{b}}\end{array}$

\begin{tabular}{|c|c|c|c|c|c|}
\hline Location: $\mathrm{H}_{2} \mathrm{~S}$ & 0.282 & 0.598 & & 25.5 & $4.96 \times 10^{-6}$ \\
\hline Location: RH & 10.5 & 0.002 & $* *$ & 3.71 & 0.059 \\
\hline $\mathbf{H}_{2} \mathrm{~S}: \mathbf{R H}$ & 1.09 & 0.302 & & 1.05 & 0.311 \\
\hline Location: Temp & 3.26 & 0.078 & & 2.00 & 0.163 \\
\hline $\mathrm{H}_{2} \mathrm{~S}:$ Temp & 0.007 & 0.933 & & 3.06 & 0.086 \\
\hline RH: Temp & 0.072 & 0.79 & & 1.53 & 0.222 \\
\hline
\end{tabular}

a $\operatorname{Pr}(>\mathrm{F})$ is the probability value using the F-test.

Among the input variables, significant interaction was found between Location and $R H$ for the prediction of corrosion initiation time, and between Location and $H_{2} S$ for the prediction of corrosion rate. This indicates that, for GP and PS coupons, the impacts of relative humidity and $\mathrm{H}_{2} \mathrm{~S}$ are different for the corrosion initiation time and corrosion rate, respectively.

The interactions may be caused by: (1) the water content inside the concrete, where the PS coupons had a constant water supply from the wastewater while the GP coupons were mostly wetted by condensation; (2) the wastewater inoculation frequency which provided frequent supply of microorganisms and nutrients for PS coupons, while the GP coupons were rarely inoculated.

During the initiation stage of sewer corrosion, carbonation and hydrogen sulfide dissolution can reduce the initial high $\mathrm{pH}$ of concrete. The water layer on concrete surface would be essential for this process. After the $\mathrm{pH}$ is lowered to around 8, microorganisms would colonize the concrete surface (Li et al., 2017). Water content, nutrient supply and microbial inoculation are important for the growth and the development of the corrosion inducing microbial communities. Distinct microbial communities are reported in corrosion layers 
and these are associated with corrosion rates in laboratory and field studies of the sewer environment (Jiang et al., 2016b; Cayford et al., 2017).

\subsection{Prediction of the corrosion initiation time- $t_{\mathrm{i}}$}

Due to the interaction between Location and $R H$ on the prediction of corrosion initiation time, MLR models were established by using separated GP or PS data or by introducing the Location*RH into the model (The graphical outputs of MLR models were shown in (Figure S-2).

Table 2). The graphical outputs of MLR models were shown in (Figure S-2).

Table 2. MLR models built using either the full dataset or location specific data for the prediction of initiation time $\left(t_{i}\right.$, month)

\begin{tabular}{|c|c|c|c|}
\hline Dataset & Interaction & Model & $\mathbf{R}^{2}$ \\
\hline Full dataset & - & $t_{\mathrm{i}}=96.34+1.68 *$ Location $-0.18 * \mathrm{H}_{2} \mathrm{~S}-0.54 * \mathrm{RH}-0.84 * \mathrm{~T}$ & 0.54 \\
\hline GP dataset & - & $t_{\mathrm{i}}=147.7-0.160 * H_{2} S-1.01 * R H-1.08^{*} T$ & 0.76 \\
\hline PS dataset & - & $t_{\mathrm{i}}=44.94-0.208 * H_{2} S-0.0708 * R H-0.592 * T$ & 0.42 \\
\hline \multirow[t]{2}{*}{ Full dataset } & Location: RH & $t_{\mathrm{i}}=96.34+46.07 *$ Location $-0.184 * H_{2} S-0.538 * R H-$ & 0.62 \\
\hline & & $0.835^{*} T-0.467 *$ Location $^{*} R H$ & \\
\hline
\end{tabular}

Comparing the first model, built using the whole dataset, with the models built on the separated datasets, changed the $\mathrm{R}^{2}$ value from 0.54 to 0.76 and to 0.42 for GP and PS coupons respectively (Table 2). This indicates that the MLR model performs better in predicting the corrosion initiation time of the GP coupons 
than of the PS coupons. In comparison to the GP coupons, the coefficient of RH for PS coupons was around 14 times lower. Similarly, after including the Location* $R H$ into the model, the $\mathrm{R}^{2}$ for the model of the whole dataset increased from 0.54 to 0.62 and under the same $\mathrm{H}_{2} \mathrm{~S}$ and $\mathrm{T}$, the RH had higher influence on the corrosion initiation time for the GP coupons. Based on the model coefficients of $\mathrm{H}_{2} \mathrm{~S}$ and T on PS and GP coupons (Table 2), a higher impact of $\mathrm{H}_{2} \mathrm{~S}$ concentration and a lower impact of gas temperature was found on the corrosion initiation time for the PS coupons.

As described in section 3.1, the initiation of corrosion is mainly caused by chemical reactions between the concrete, $\mathrm{H}_{2} \mathrm{~S}$ and $\mathrm{CO}_{2}$ (Jiang et al., 2016a). The MLR model suggests that the moisture content in the concrete was the key factor that influenced the corrosion initiation process. Concrete contains extensive pore structures which will form pathways for moisture, $\mathrm{CO}_{2}$ and $\mathrm{H}_{2} \mathrm{~S}$ to move from the external environment to the inner parts of the concrete surface. For the PS coupons, they encounter direct contact with the wastewater while the GP coupons would only obtain moisture from condensation of water. Although exposed to the same sewer gas, due to the higher moisture content, more $\mathrm{CO}_{2}$ and $\mathrm{H}_{2} \mathrm{~S}$ would diffuse from the sewer gas onto the PS coupons in comparison to the GP coupons. This would induce shorter corrosion initiation time for the PS coupons. In addition, as the PS coupons were in contact with wastewater, the gas temperature would have less influence on the reactions at the concrete surface.

Following the regression analysis, ANN and ANFIS models were built for predicting the corrosion initiation time using the same dataset. The final structure of the ANN model was established as 4 input, 7 hidden, and 1 output neurons in MATLAB (R2015b). For the ANFIS model, grid partitioning was used to cluster the data for the purpose of prediction in MATLAB. Correlations between the target and output of the corrosion initiation time for the training, testing, and validation steps, and for the complete data set of initiation time, were determined using the ANN and ANFIS models (Figure 1 and Figure 2). 

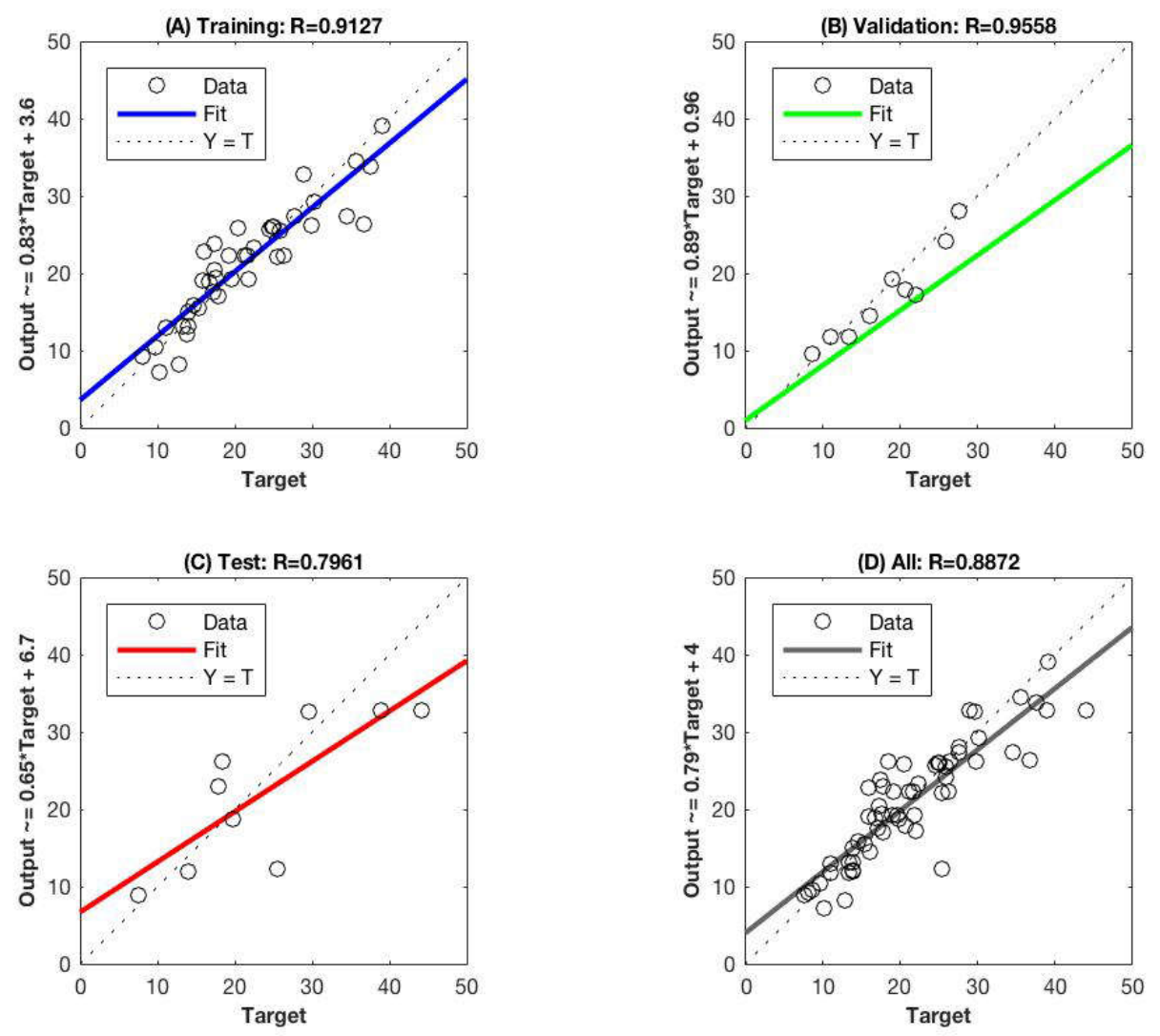

343 Figure 1. The outputs of the ANN model and correlation to measured corrosion initiation time using training

344 (A), validation (B) test (C), and the complete (D) data sets. Target is the concrete corrosion initiation time

345 ( $t_{i}$, month) determined from coupons exposed to conditions simulating environments in sewers using

346 laboratory corrosion chambers. Output is the value obtained from the model predicting the corrosion

347 initiation time based on the environment condition. The $\mathrm{Y}=\mathrm{T}$ line is where the $\mathrm{y}$-axis value equals to the target value. 

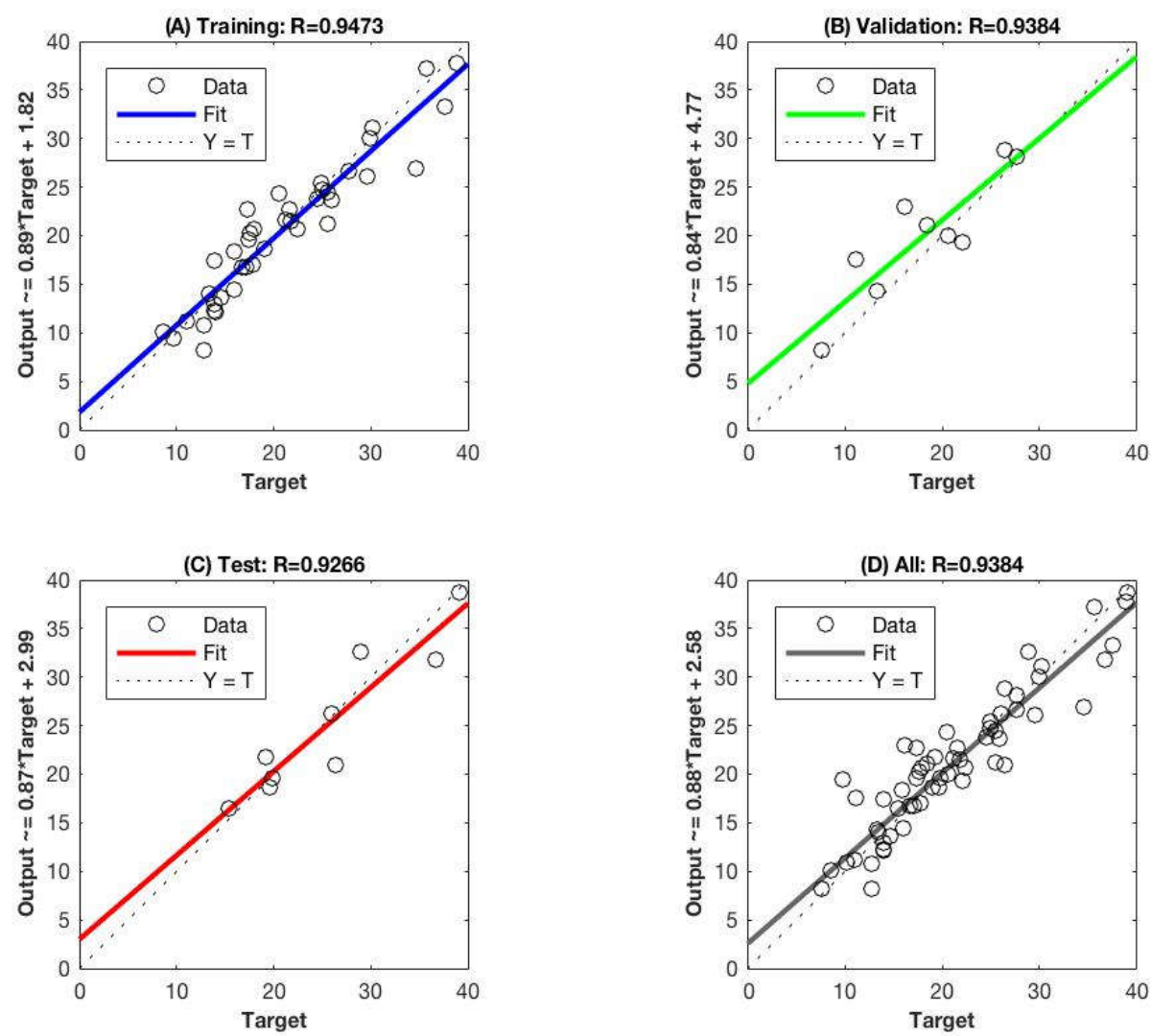

350 Figure 2. The outputs of the ANFIS model and correlation to measured corrosion initiation time using training (A), validation (B), test (C), and the complete (D) data sets. Target is the concrete corrosion initiation time $\left(t_{i}\right.$, month) determined from coupons exposed to conditions simulating environments in sewers using laboratory corrosion chambers. Output is the value obtained from the model predicting the corrosion initiation time based on the environment condition. The $\mathrm{Y}=\mathrm{T}$ line is where the $\mathrm{y}$-axis value equals to the target value.

Both the ANN and ANFIS models achieved satisfactory performance in predicting the corrosion initiation time. The $\mathrm{R}$ values obtained for the models using the complete data set were 0.8872 and 0.9384 , respectively.

358 Similar results were observed in the training, validation and testing steps of the models. This indicates that both the ANN and ANFIS models were capable of predicting the relationship between the corrosion initiation time and the chosen sewer environmental factors. It was also observed that the ANFIS model 
showed slightly better performance than the ANN model. This was for prediction using the training data, validation data, test data and the complete data sets (Figure 2A, B, C, D). This improved predicting performance of the ANFIS model was not unexpected as it has a more complicated model structure by inclusion of the fuzzy inference system with ANN.

For the application of these ANN and ANFIS based models, it is worth noting that the input variables chosen are important for the prediction but may not be limited to these four factors used here, those of location, $\mathrm{H}_{2} \mathrm{~S}, \mathrm{RH}$ and temperature. Additionally, the data-driven models performed reasonable predictions within the range of conditions investigated in the laboratory corrosion chambers. However, with inclusion of more detailed data, such as real sewer conditions of fluctuations of $\mathrm{H}_{2} \mathrm{~S}, \mathrm{RH}$ and temperature or more input variables (i.e. properties of concrete), this would further improve the model performance.

\subsection{Prediction of the corrosion rate-r}

Based on the interaction analysis (

Table 1), six MLR models were built using the whole dataset, the gas phase dataset, the partially submerged dataset, with and without the interaction between location and $\mathrm{H}_{2} \mathrm{~S}$ The graphical outputs of MLR models were shown in (Figure S-3).

Table 3). The graphical outputs of MLR models were shown in (Figure S-3).

\section{Table 3. MLR Models built with the complete dataset and location specific dataset for prediction of} corrosion rate $(r, \mathrm{~mm} / \mathrm{year})$ 


\begin{tabular}{llll}
\hline Full dataset & - & $r=-0.173-0.453 *$ Location $+0.0282 * H_{2} S+0.0087 * R H-$ & 0.61 \\
& & $0.0157 * T$ \\
GP data & - & $r=-1.96+0.0119 * H_{2} S+0.0293 * R H+0.0016 * T$ & 0.51 \\
PS data & - & $r=1.61+0.0446 * H_{2} S-0.119 * R H+0.0299 * T$ & 0.64 \\
Full dataset & Location: $\mathrm{H}_{2} \mathrm{~S}$ & $r=-0.173-0.167 *$ Location $+0.0283 * H_{2} S+0.0869 * R H-$ & 0.71 \\
& & $0.0157 * T-0.0164 * H_{2} S *$ Location &
\end{tabular}

382 Similarly, for the prediction of corrosion rate $(r, \mathrm{~mm} / \mathrm{year})$, two approaches were used. One approach established models for the full dataset, and the GP and PS separately, the second included the interaction of Location ${ }^{*} \mathrm{H}_{2} \mathrm{~S}$ into the full dataset model. After separating the datasets, the $\mathrm{R}^{2}$ value changed from 0.61 to 0.51 and 0.64 for GP coupons and PS coupons, respectively (Table 3). Suggesting that the MLR model performed better in predicting the corrosion rate of the PS coupons in comparison to the GP coupons. After including the interaction for Location* $\mathrm{H}_{2} \mathrm{~S}$ into the MLR model, the $\mathrm{R}^{2}$ for the full dataset increased from 0.61 to 0.71 . With this inclusion, the $\mathrm{H}_{2} \mathrm{~S}$ had more severe influence on the corrosion rate of the PS coupons, 3.8 times higher than GP coupons, under the same $\mathrm{H}_{2} \mathrm{~S}$ and T. This corroborates the observation that under the same conditions, the corrosion is always more severe on the partially submerged concrete in comparison to the gas phase concrete (Jiang et al., 2016b). After the corrosion initiation period, the corrosion rate can be influenced by the activities of the sulfur-oxidizing microorganisms. These will utilize the gas phase $\mathrm{H}_{2} \mathrm{~S}$ that diffuses into the biofilm for their growth and produce sulfuric acid (Li et al., 2017). The increased influence of $\mathrm{H}_{2} \mathrm{~S}$ on the corrosion rate of the PS coupons may be culminating from effects of the repeated inoculum from the wastewater resulting in higher microbial activity and increased moisture content of the concrete. 
The best architecture of the ANN model for the corrosion rate was determined using four input neurons.

398 These were 3 hidden layer neurons and 1 output neuron determined by exhaustive searching. The ANFIS 399 model for the corrosion rate was built using the same approach as section 3.1. Correlations between the target and output of the corrosion rates for the training, validation and test data, and for the complete data sets of corrosion rates were determined using the ANN and ANFIS models
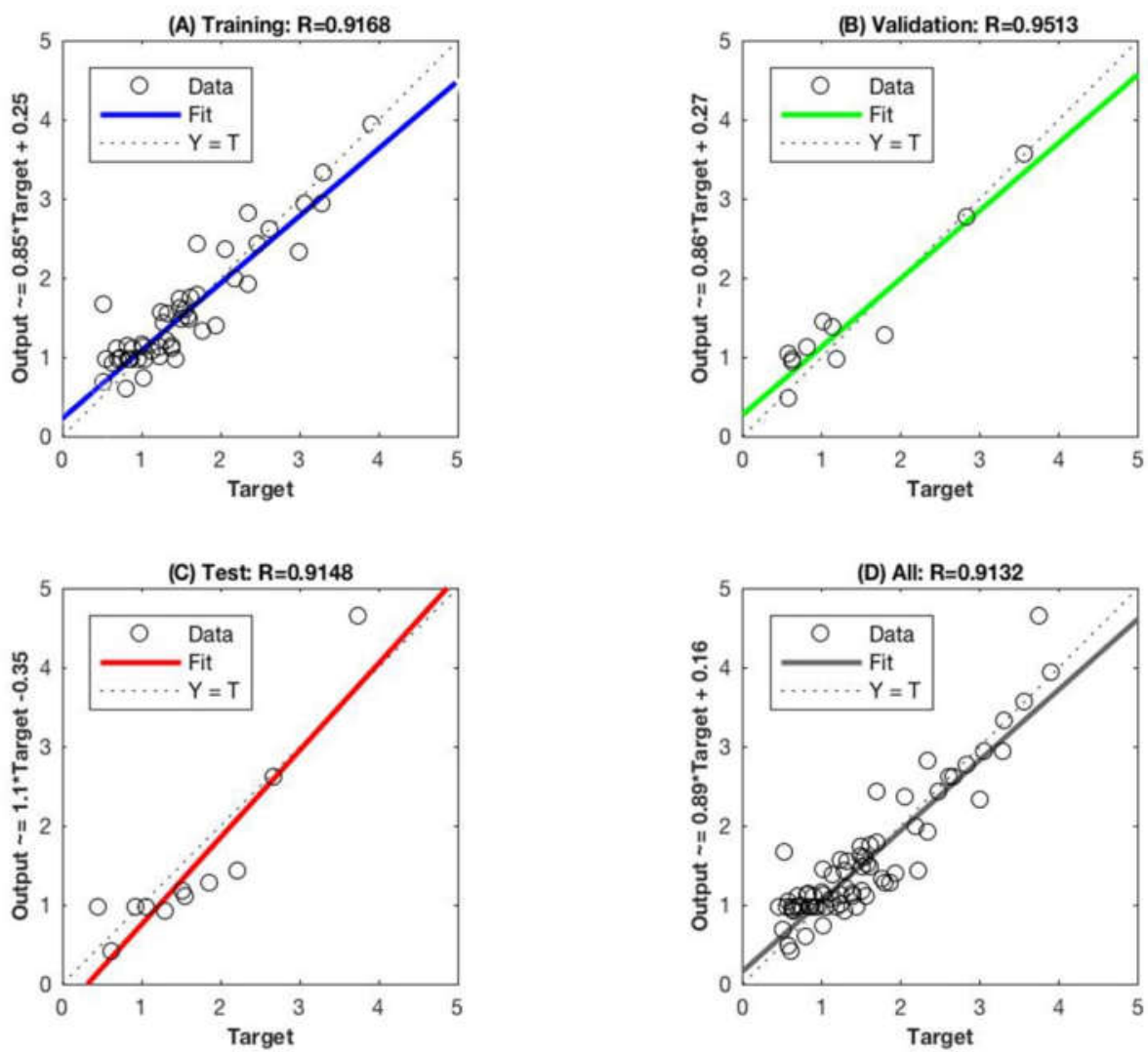

402

Figure 3 and Figure 4). 

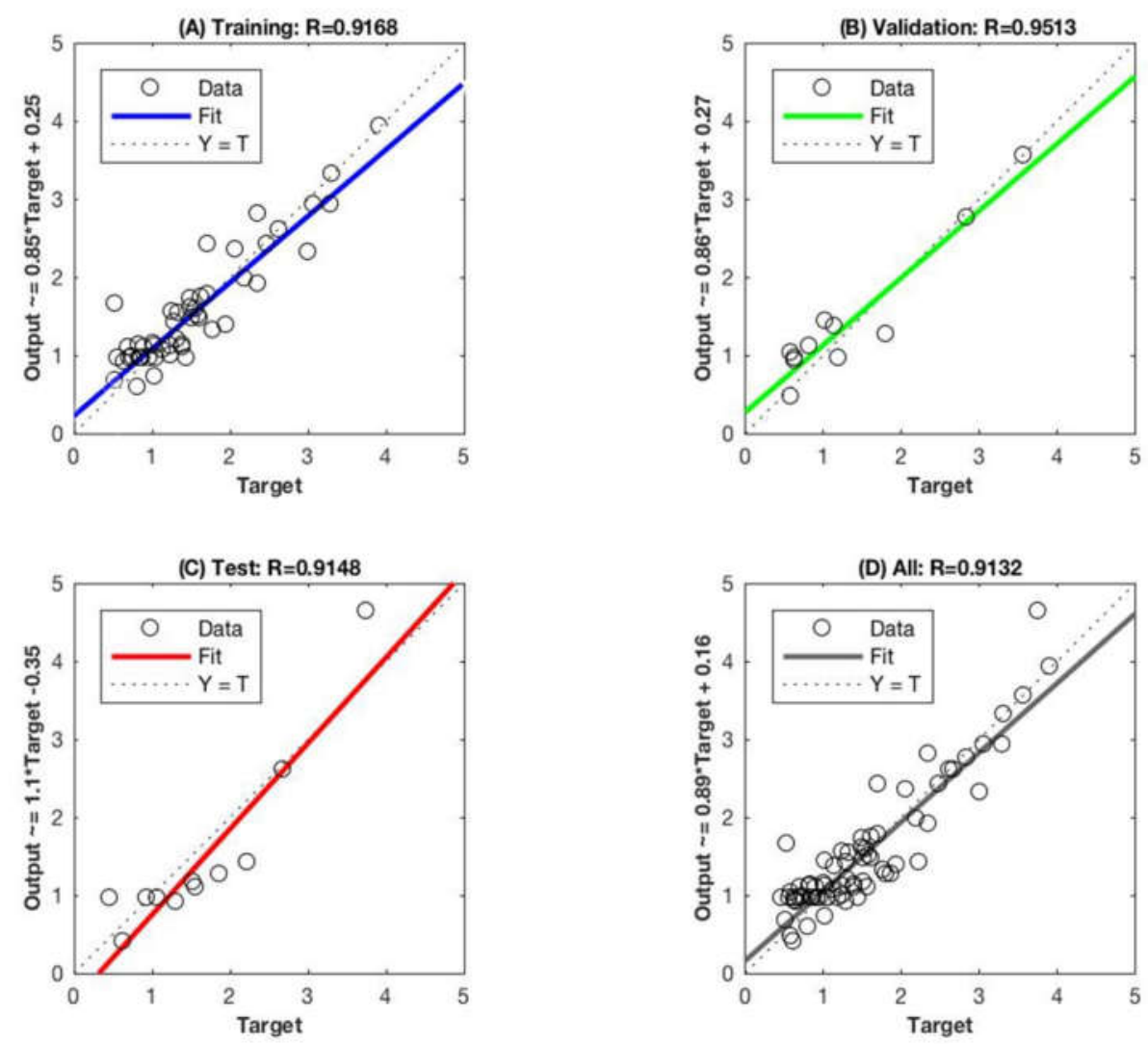

405 Figure 3. The outputs of the ANN model and correlation with measured corrosion rate using training (A), 406 validation (B) and test (C), and the complete (D) data sets. Target is the concrete corrosion rate ( $r$, mm/year) 407 determined from coupons exposed to conditions simulating environments in sewers using laboratory 408 corrosion chambers. Output is the value obtained from the model predicting the corrosion rate based on 409 the environment condition. The $\mathrm{Y}=\mathrm{T}$ line is where the $\mathrm{y}$-axis value equals to the target value. 

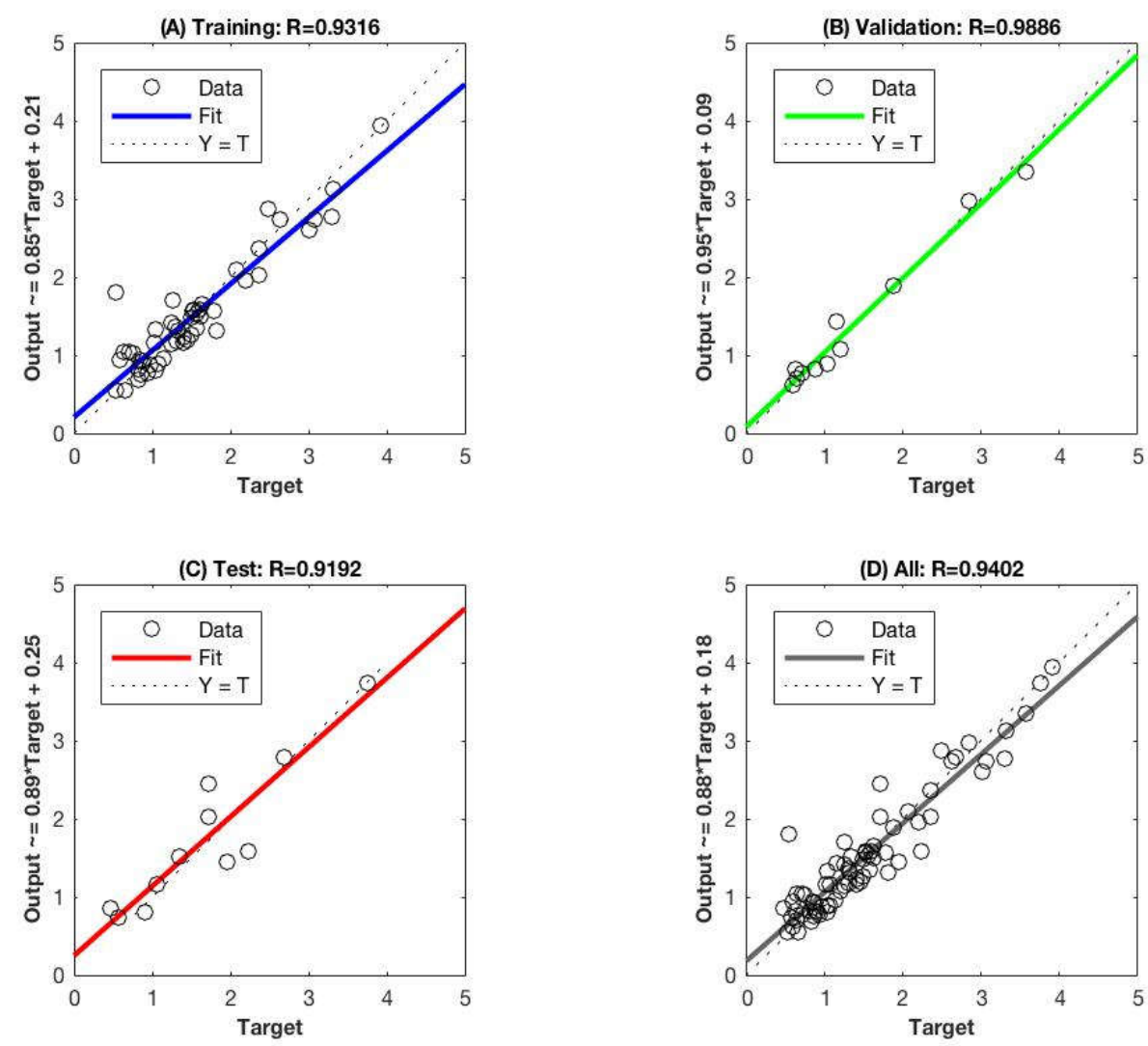

411 Figure 4. The outputs of the ANFIS model and correlation with measured corrosion rate using training (A),

412 validation (B), test (C) and the complete data (D) sets. Target is the concrete corrosion rate ( $r, \mathrm{~mm} /$ year)

413 determined from coupons exposed to conditions simulating environments in sewers using laboratory corrosion chambers. Output is the value obtained from the model predicting the corrosion rate based on

415 the environment condition. The $\mathrm{Y}=\mathrm{T}$ line is where the $\mathrm{y}$-axis value equals to the target value.

416 Both the ANN and ANFIS models achieved very high levels of performance using the different datasets 417 for training, validation and test steps. ANFIS also slightly increased the accuracy of corrosion rate prediction, as evident by the high $\mathrm{R}$ at 0.9402 in comparison to 0.9102 for the ANN model. The good performance of ANN and ANFIS models for corrosion rate prediction confirms that these data-driven models can be very useful in predicting the sewer service life using the data from laboratory corrosion 
422 conditions, would be essential for application of the DDM in real sewer conditions.

\subsection{Sensitivity analysis of DDM with partial input data}

424

After developing the ANN and ANFIS models to predict the corrosion initiation time $\left(t_{\mathrm{i}}\right)$ and corrosion rate ( $r$ ) using the laboratory data, a further step was carried out to build MLR, ANN and ANFIS models with limited input factors under twelve different combination scenarios (

Table 4). According to the results of interaction analysis (section 3.1), to improve the performance of MLR models, Location $* \mathrm{RH}$ and Location $* \mathrm{H}_{2} \mathrm{~S}$ were also included for prediction of $t_{i}$ and $r$, respectively and the $\mathrm{R}^{2}$ values for all these models MLR models with interaction factors (MLRI) were determined (

\section{Table 4).}

\section{Table 4. Coefficient of determination $\left(\mathrm{R}^{2}\right)$ determined for sensitivity analysis using data-driven models} (MLR; MLRI: MLR with interaction; ANN; ANFIS) in predicting $t_{i}$ and $r$ with partial input parameters

Coefficient of determination $\left(\mathbf{R}^{2}\right)$

\section{Scenario}

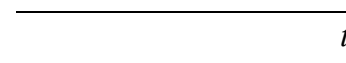

$t_{\mathrm{i}}$

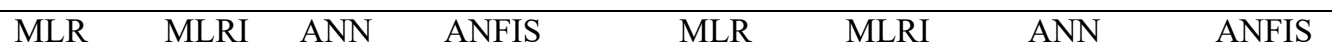

\begin{tabular}{|c|c|c|c|c|c|c|c|c|c|}
\hline 1 & $\begin{array}{l}\text { Loc }^{\mathrm{a}}, \mathrm{T}, \mathrm{H}_{2} \mathrm{~S}, \\
\mathrm{RH}\end{array}$ & 0.54 & 0.62 & 0.79 & 0.88 & 0.61 & 0.71 & 0.83 & 0.88 \\
\hline 2 & $\mathrm{~T}, \mathrm{H}_{2} \mathrm{~S}, \mathrm{RH}$ & 0.51 & $\mathrm{~N} / \mathrm{A}$ & 0.48 & 0.59 & 0.32 & N/A & 0.36 & 0.41 \\
\hline 3 & Loc, $\mathrm{H}_{2} \mathrm{~S}, \mathrm{~T}$ & 0.44 & $\mathrm{~N} / \mathrm{A}$ & 0.51 & 0.52 & 0.60 & 0.71 & 0.77 & 0.81 \\
\hline 4 & Loc, $\mathrm{H}_{2} \mathrm{~S}, \mathrm{RH}$ & 0.22 & 0.34 & 0.38 & 0.43 & 0.60 & 0.70 & 0.75 & 0.78 \\
\hline 5 & Loc, RH, T & 0.42 & 0.50 & 0.46 & 0.51 & 0.30 & N/A & 0.33 & 0.35 \\
\hline
\end{tabular}


6 Loc, $\mathrm{H}_{2} \mathrm{~S}$

0.16

N/A

0.19

0.19

0.60

0.70

0.74

0.74

7 Loc, T

0.32

N/A

0.35

0.32

0.30

N/A

0.3

0.31

8 Loc, RH

0.14

0.22

0.22

0.18

0.29

N/A

0.30

0.31

9 Loc

0.04

N/A

0.04

0.03

0.29

N/A

0.29

$10 \mathrm{RH}$

0.10

N/A

0.10

0.08

0.03

N/A

0.27

0.35

$11 \mathrm{~T}$

0.28

N/A

0.29

0.27

0.10

N/A

0.01

0.01

$12 \mathrm{H}_{2} \mathrm{~S}$

0.12

N/A

0.18

0.15

0.31

N/A

0.35

0.01

${ }^{\mathrm{a}}$ Loc: location.

For the prediction of $t_{\mathrm{i}}$, ANN and ANFIS showed better performance than MLR with all four inputs.

However, with the lack of any one of the four input parameters, ANN and ANFIS models showed similar accuracy of prediction to MLR models. It was also noted that all the DDM tested for $t_{\mathrm{i}}$ were sensitive to the partial input data. Therefore, for the accuracy of prediction for $t_{\mathrm{i}}$, it is essential to collect as much sewer environmental data as possible.

In contrast, the DDM for predicting corrosion rates were quite robust when only partial inputs were fed to the models. The models under scenarios 1, 3, 4 and 6 all showed good performance with reasonable $\mathrm{R}^{2}$ values (Table 4). The prediction of corrosion rate relied on two key input parameters, location and $\mathrm{H}_{2} \mathrm{~S}$ concentration. Previously, minimum adequate models based on these two parameters were shown to give good predictions of corrosion rate (Jiang et al., 2014). Considering there are only two corrosion hotspots, i.e. the tidal zone and the crown zone, and that the corrosion initiation time is minor compared to the whole sewer service life, the prediction of sewer service life can then be adequately achieved using only the hydrogen sulfide concentration. This can be very useful for providing a reasonable estimation of the sewer corrosion rate and service life especially when, as in most cases, the physical inspection of the sewer is difficult. 
451 This study developed and evaluated three data-driven models for the prediction of sewer service life based on the estimation of the corrosion initiation time and corrosion rate. The performance of the models were

453 evaluated using extensive datasets of concrete corrosion determined from laboratory chambers simulating sewer conditions. The sensitivity of these models to partial input data was also analyzed to determine their robustness in real applications. It is concluded that:

- The cross-sectional location in a sewer pipe had significant correlation with the impact of relative humidity and $\mathrm{H}_{2} \mathrm{~S}$ concentration on the prediction of corrosion initiation time and corrosion rate, respectively.

- ANN and ANFIS models performed better than the MLR model for the corrosion prediction, with or without considering the interactions among environmental factors.

- Prediction of corrosion initiation time was sensitive to partial inputs while the models were robust in predicting corrosion rate using partial input data.

- Sewer service life can be reasonably predicted by using just the $\mathrm{H}_{2} \mathrm{~S}$ concentration as the single input in all the three data-driven models.

Notes:

The authors declare no competing interests. 
473

The authors acknowledge the financial support provided by the Australian Research Council and many members of the Australian water industry through LP0882016 the Sewer Corrosion and Odour Research (SCORe) Project (www.score.org.au) and the LP150101337. Dr Guangming Jiang is the recipient of a Queensland State Government's Early Career Accelerate Fellowship and an Australian Research Council DECRA Fellowship (DE170100694). Xuan Li acknowledges the Chinese Scholarship Council for providing the Living Allowance Scholarship.

\section{References}

Abdulshahed, A.M., Longstaff, A.P., and Fletcher, S. (2015). The application of ANFIS prediction models for thermal error compensation on CNC machine tools. Applied Soft Computing 27, 158-168.

Alexander, M., Bertron, A., and De Belie, N. (2013). Performance of cement-based materials in aggressive aqueous environments. Springer.

Amani, J., and Moeini, R. (2012). Prediction of shear strength of reinforced concrete beams using adaptive neuro-fuzzy inference system and artificial neural network. Scientia Iranica 19, 242248.

Baur, R., and Herz, R. (2002). Selective inspection planning with ageing forecast for sewer types. Water science and technology 46, 389-396.

Cayford, B.I., Jiang, G., Keller, J., Tyson, G., and Bond, P.L. (2017). Comparison of microbial communities across sections of a corroding sewer pipe and the effects of wastewater flooding. Biofouling 33, 780-792.

Chang, F.-J., and Chang, Y.-T. (2006). Adaptive neuro-fuzzy inference system for prediction of water level in reservoir. Advances in Water Resources 29, 1-10.

Chang, Z.-T., Song, X.-J., Munn, R., and Marosszeky, M. (2005). Using limestone aggregates and different cements for enhancing resistance of concrete to sulphuric acid attack. Cement and Concrete Research 35, 1486-1494.

Dalmau, M., Atanasova, N., Gabarrón, S., Rodriguez-Roda, I., and Comas, J. (2015). Comparison of a deterministic and a data driven model to describe MBR fouling. Chemical Engineering Journal 260, 300-308.

De Muynck, W., De Belie, N., and Verstraete, W. (2009). Effectiveness of admixtures, surface treatments and antimicrobial compounds against biogenic sulfuric acid corrosion of concrete. Cement and Concrete Composites 31, 163-170.

Deshpande, N., Londhe, S., and Kulkarni, S. (2014). Modeling compressive strength of recycled aggregate concrete by artificial neural network, model tree and non-linear regression. International Journal of Sustainable Built Environment 3, 187-198.

Ganigue, R., Gutierrez, O., Rootsey, R., and Yuan, Z. (2011). Chemical dosing for sulfide control in Australia: an industry survey. Water research 45, 6564-6574. 
Garzón-Roca, J., Marco, C.O., and Adam, J.M. (2013). Compressive strength of masonry made of clay bricks and cement mortar: Estimation based on Neural Networks and Fuzzy Logic. Engineering Structures 48, 21-27.

Jiang, G., Gutierrez, O., Sharma, K.R., Keller, J., and Yuan, Z. (2011). Optimization of intermittent, simultaneous dosage of nitrite and hydrochloric acid to control sulfide and methane productions in sewers. Water research 45, 6163-6172.

Jiang, G., Keating, A., Corrie, S., O'halloran, K., Nguyen, L., and Yuan, Z. (2013). Dosing free nitrous acid for sulfide control in sewers: results of field trials in Australia. Water research 47, 4331-4339.

Jiang, G., Keller, J., and Bond, P.L. (2014). Determining the long-term effects of $\mathrm{H}_{2} \mathrm{~S}$ concentration, relative humidity and air temperature on concrete sewer corrosion. Water Res 65, 157-169.

Jiang, G., Keller, J., Bond, P.L., and Yuan, Z. (2016a). Predicting concrete corrosion of sewers using artificial neural network. Water Res 92, 52-60.

Jiang, G., Melder, D., Keller, J., and Yuan, Z. (2017). Odor emissions from domestic wastewater: A review. Critical Reviews in Environmental Science and Technology 47, 1581-1611.

Jiang, G., Sun, J., Sharma, K.R., and Yuan, Z. (2015a). Corrosion and odor management in sewer systems. Current Opinion in Biotechnology 33, 192-197.

Jiang, G., Sun, X., Keller, J., and Bond, P.L. (2015b). Identification of controlling factors for the initiation of corrosion of fresh concrete sewers. Water Research 80, 30-40.

Jiang, G., Zhou, M., Chiu, T.H., Sun, X., Keller, J., and Bond, P.L. (2016b). Wastewater Enhanced Microbial Corrosion of Concrete Sewers. Environ Sci Technol.

Joseph, A.P., Keller, J., Bustamante, H., and Bond, P.L. (2012). Surface neutralization and $\mathrm{H}_{2} \mathrm{~S}$ oxidation at early stages of sewer corrosion: influence of temperature, relative humidity and $\mathrm{H}_{2} \mathrm{~S}$ concentration. Water research 46, 4235-4245.

Kaempfer, W., and Berndt, M. (1999). Estimation of service life of concrete pipes in sewer networks. Durability of Building Materials and Components 8, 36-45.

Karaboga, D., and Kaya, E. (2018). Adaptive network based fuzzy inference system (ANFIS) training approaches: a comprehensive survey. Artificial Intelligence Review, 1-31.

Khademi, F., and Behfarnia, K. (2016). Evaluation of concrete compressive strength using artificial neural network and multiple linear regression models. Iran University of Science \& Technology 6, 423432.

Khademi, F., and Jamal, S.M. (2016). Predicting the 28 days compressive strength of concrete using artificial neural network. i-Manager's Journal on Civil Engineering 6, 1.

Li, X., Jiang, G., Kappler, U., and Bond, P. (2017). The ecology of acidophilic microorganisms in the corroding concrete sewer environment. Frontiers in Microbiology 8, 683.

Madandoust, R., Bungey, J.H., and Ghavidel, R. (2012). Prediction of the concrete compressive strength by means of core testing using GMDH-type neural network and ANFIS models. Computational Materials Science 51, 261-272.

Nielsen, A.H., Vollertsen, J., and Hvitved-Jacobsen, T. (2003). Determination of kinetics and stoichiometry of chemical sulfide oxidation in wastewater of sewer networks. Environmental science \& technology 37, 3853-3858.

Parker, C. (1945). The corrosion of concrete 2. The function of Thiobacillus concretivorus (nov. spec.) in the corrosion of concrete exposed to atmospheres containing hydrogen sulphide. Australian Journal of Experimental Biology \& Medical Science 23.

Sadowski, L., and Nikoo, M. (2014). Corrosion current density prediction in reinforced concrete by imperialist competitive algorithm. Neural Computing and Applications 25, 1627-1638.

Sharma, K., De Haas, D.W., Corrie, S., O’halloran, K., Keller, J., and Yuan, Z. (2008). Predicting hydrogen sulfide formation in sewers: a new model. Water 35, 132-137. 
Song, Y., Wightman, E., Tian, Y., Jack, K., Li, X., Zhong, H., Bond, P.L., Yuan, Z., and Jiang, G. (2018). Corrosion of reinforcing steel in concrete sewers. Science of The Total Environment.

Sun, X., Jiang, G., Bond, P.L., Keller, J., and Yuan, Z. (2015). A novel and simple treatment for control of sulfide induced sewer concrete corrosion using free nitrous acid. Water Res 70, 279-287.

Tee, K.F., Li, C.Q., and Mahmoodian, M. (Year). "Prediction of time-variant probability of failure for concrete sewer pipes", in: Proc. of the 12 th International Conference on Durability of Building Materials and Components), 12-15.

Topcu, I.B., and Sarıdemir, M. (2008). Prediction of compressive strength of concrete containing fly ash using artificial neural networks and fuzzy logic. Computational Materials Science 41, 305-311.

Wang, Y.-M., and Elhag, T.M. (2008). An adaptive neuro-fuzzy inference system for bridge risk assessment. Expert systems with applications 34, 3099-3106.

Wells, T., and Melchers, R. (2014). An observation-based model for corrosion of concrete sewers under aggressive conditions. Cement and Concrete Research 61, 1-10.

Wells, T., Melchers, R., Joseph, A., Bond, P., Vitanage, D., Bustamante, H., De Grazia, J., Kuen, T., Nazimek, J., and Evans, T. (Year). "A collaborative investigation of the microbial corrosion of concrete sewer pipe in Australia", in: OzWater-12 Australia's National Water Conference and Exhibition, May), 8-10.

Wells, T., and Melchers, R.E. (2015). Modelling concrete deterioration in sewers using theory and field observations. Cement and Concrete Research 77, 82-96.

Zhang, L., Keller, J., and Yuan, Z. (2009). Inhibition of sulfate-reducing and methanogenic activities of anaerobic sewer biofilms by ferric iron dosing. Water Research 43, 4123-4132. 